\title{
Dynamin-related protein 1 is implicated in endoplasmic reticulum stress-induced pancreatic $\beta$-cell apoptosis
}

\author{
LIANG PENG ${ }^{1 *}$, XIULI MEN ${ }^{2 *}$, WENJIAN ZHANG ${ }^{1}$, HAIYAN WANG $^{3}$, SHIQING XU $^{1}$, \\ MEI XU ${ }^{1}$, YAPING XU ${ }^{1}$, WENYING YANG ${ }^{1}$ and JINNING LOU ${ }^{1}$ \\ ${ }^{1}$ Institute of Clinical Medical Sciences, China-Japan Friendship Hospital, Beijing 100029; ${ }^{2}$ Department of \\ Pathophysiology, North China Coal Medical University, Tangshan 063000, P.R. China; ${ }^{3}$ Department of \\ Cell Physiology and Metabolism, University Medical Center, CH-1211 Geneva 4, Switzerland
}

Received November 23, 2010; Accepted January 20, 2011

DOI: $10.3892 / \mathrm{ijmm} .2011 .684$

\begin{abstract}
Pancreatic $\beta$-cell dysfunction is a critical component in the pathogenesis of diabetes. Endoplasmic reticulum (ER) stress is one of the factors that induces pancreatic $\beta$-cell dysfunction, but the underlying mechanisms have not been well elucidated. In this study, we report that a mitochondrial fission modulator, dynamin-related protein 1 (DRP-1), plays an important role in ER stress-induced $\beta$-cell apoptosis. Induction of DRP-1 expression significantly promoted ER stress-induced apoptosis in the DRP-1 WT (DRP-1 wildtype) inducible $\beta$-cell line, but not in the DRP-1 K38A (a dominant negative mutant of DRP-1) inducible $\beta$-cell line. We further demonstrated that the mitochondrial membrane potential decreased, and that cytochrome c release, caspase-3 activation and generation of reactive oxygen species (ROS) were enhanced by induction of DRP-1 WT, but prevented by DRP-1 K38A in pancreatic $\beta$-cells under ER stress conditions. These results indicate that DRP-1 mediates ER stress-induced pancreatic $\beta$-cell apoptosis.
\end{abstract}

\section{Introduction}

Pancreatic $\beta$-cell dysfunction is a critical component in the progression of type 2 diabetes. In addition, $\beta$-cell apoptosis is considered as one of the main reasons of $\beta$-cell dysfunction $(1,8)$. Endoplasmic reticulum (ER) stress has been suggested as a causing factor of $\beta$-cell dysfunction and apoptosis (2-6). However, the underlying mechanisms remain to be elucidated.

It has been proposed that impaired mitochondrial function might be involved in cell apoptosis (7-10). The GTP-binding

Correspondence to: Professor Jinning Lou, Institute of Clinical Medical Sciences, China-Japan Friendship Hospital, Beijing 100029, P.R. China

E-mail: lou.j@mail.com

*Contributed equally

Key words: dynamin-related protein-1, diabetes, endoplasmic reticulum stress, pancreatic $\beta$-cell, apoptosis protein, dynamin-related protein 1 (DRP-1) is a mitochondrial fission protein. It has been found that expression of DRP-1 promotes mitochondrial fragmentation, while the expression of a dominant-negative form of DRP-1 inhibits mitochondrial fission and thereby apoptosis $(11,12)$. Our previous studies have demonstrated that high glucose levels increase DRP-1 expression and yield DRP-1-induced mitochondrial fission resulting in mitochondrial fragmentation and apoptosis in pancreatic $\beta$-cells, while the DRP-1 dominant-negative mutant impedes fission and apoptosis. However, whether DRP-1 is also implicated in ER stress-induced pancreatic $\beta$-cell apoptosis has not been investigated (13).

In order to clarify the possible involvement of DRP-1 in ER stress-induced $\beta$-cell dysfunction and apoptosis, we applied the established two stable pancreatic $\beta$-cell lines that could respectively induce the expression of wild-type DRP-1 (DRP-1 WT) and its dominant-negative mutant (DRP-1 K38A) to investigate the role of DRP-1 on ER stressinduced $\beta$-cell apoptosis. In addition, the related mechanisms of DRP-1 mediated pancreatic $\beta$-cell apoptosis were further analyzed through the assessment of various morphological and functional parameters.

\section{Materials and methods}

Establishment of INS-1 stable cell lines allowing inducible expression of DRP-1 WT and DRP-1 K38A. The plasmids were constructed by subcloning the cDNAs encoding, respectively, Drp-1 WT and Drp-1 K38A. The dominant-negative mutant DRP-1 K38A, changes the critical lysine in the G1 consensus motif of the GTPase domain into an alanine, thereby presumably inhibiting GTP binding of DRP-1. This mutation has been used in a previous study of mammalian DRP-1 (14). The rat insulinoma cell line, INS-1-r $\beta$ (also referred to as $\mathrm{r} 9$ ), which carries the reverse tetracycline/doxycycline-dependent transactivator (15), was generated using the procedures described previously $(16,17)$. The DRP-1 WT and DRP-1 K38A cell lines were cultured in complete medium composed of RPMI-1640 (Gibco) supplemented with $10 \mathrm{mM}$ HEPES, $10 \%$ fetal calf serum (FCS), $2 \mathrm{mM}$ L-glutamine, $100 \mathrm{U} / \mathrm{ml}$ penicillin, $100 \mu \mathrm{g} / \mathrm{ml}$ streptomycin, $1 \mathrm{mM}$ sodium pyruvate and $50 \mu \mathrm{M} 2$-mercaptoethanol. Cells were incubated 
at $37^{\circ} \mathrm{C}$ in a $5 \% \mathrm{CO}_{2}$ incubator (18) and the medium was changed every 3 days.

Real-time PCR. Total RNA samples from DRP-1 WT and DRP-1 K38A cells were analyzed by real-time PCR. PCR reactions were carried out in a volume of $25 \mu \mathrm{l}$ consisting of $2.5 \mu \mathrm{l}$ cDNA, $12.5 \mu 1$ reaction mix (SYBR-Green I dye, Toyobo) and $0.5 \mu 125 \mathrm{pmol} / 1$ oligonucleotide primers. All reactions were performed in an Applied Biosystems (ABI) instrument in which samples underwent 40 cycles of PCR at an annealing temperature of $55^{\circ} \mathrm{C}$. The following primers were used (forward and reverse, respectively): ATTGCGGATTCACTACTC and GATTTCTACTGCGACCATA (Drp-1), GACATCCGTA AAGACCTCTATGCC and AATAGAGCCACCAATCCA CACAGAG $(\beta$-actin). The value obtained for each specific product was normalized to a control gene $(\beta$-actin) and expressed as a percentage of the value in the control gene.

Immunofluorescence staining. The cells were cultured in 96-well plates at $37^{\circ} \mathrm{C}$ in a $5 \% \mathrm{CO}_{2}$ incubator for $24 \mathrm{~h}$, and then treated with or without $500 \mathrm{ng} / \mathrm{ml}$ doxycycline for induction of DRP-1 WT and DRP-1 K38A expression. After $48 \mathrm{~h}$ of incubation, the cells were fixed in $4 \%$ paraformaldehyde, permeabilized with $0.1 \%$ Triton X-100 in PBS containing $0.5 \%$ BSA (PBS/BSA) for $30 \mathrm{~min}$. The cells were subsequently incubated with anti-DRP-1 antibody (BD Transduction Laboratories, USA; 1:100 dilution) for $30 \mathrm{~min}$, followed by labeling with FITC-conjugated rat anti-mouse $\mathrm{IgG}$ antibody. The cells were viewed under a fluorescent microscope (Olympus IX71, Japan).

Western blotting. For Western blotting, cells were cultured in flasks for $48 \mathrm{~h}$ before treatment with or without $500 \mathrm{ng} / \mathrm{ml}$ doxycycline for induction of DRP-1 WT and DRP-1 K38A expression. After $48 \mathrm{~h}$, all these cells were collected and lysed by sonication. The protein was extracted in buffer containing $20 \mathrm{mM}$ Tris- $\mathrm{HCl}, \mathrm{pH}$ 7.4, 2 mM EDTA, $150 \mu \mathrm{M} \mathrm{NaCl}, 10 \mathrm{mM}$ $\mathrm{NaP}, 1 \% \mathrm{NP}-40$, and $1 \mathrm{mM}$ phenylmethylsulfonyl fluoride. Total cellular proteins were fractionated by $10 \%$ SDS-PAGE. Immunoblotting was performed with anti-DRP-1 antibody as described previously (19) using enhanced chemiluminescence (Millipore, Billerica, USA) for detection.

TUNEL staining. DRP-1 WT and DRP-1 K38A cells were cultured in 96-well plates in the presence or absence of $500 \mathrm{ng} / \mathrm{ml}$ doxycycline for $48 \mathrm{~h}$, and then treated with $0.1 \mu \mathrm{M}$ thapsigargin (TG) for $12 \mathrm{~h}$ or $4 \mu \mathrm{g} / \mathrm{ml}$ tunicamycin (TM) for $24 \mathrm{~h}$. The cells were washed, fixed in $4 \%$ paraformaldehyde and then permeabilized with $0.1 \%$ Triton X-100 in a PBS/BSA solution. The terminal deoxynucleotidyl transferase-mediated dUTP nick-end labeling (TUNEL) assay was performed using in situ cell death detection kits (Roche, USA).

DNA fragmentation. DRP-1 WT and DRP-1 K38A cells were planted in 6-well plates and cultured in the presence or absence of $500 \mathrm{ng} / \mathrm{ml}$ doxycycline for $48 \mathrm{~h}$, and then treated with $0.1 \mu \mathrm{M}$ TG for $12 \mathrm{~h}$ or $4 \mu \mathrm{g} / \mathrm{ml} \mathrm{TM}$ for $24 \mathrm{~h}$. The cells were washed twice with PBS, re-suspended in the lysis buffer $(10 \mathrm{mM}$ Tris- $\mathrm{HCl}, \mathrm{pH} 8.0$ and $10 \mathrm{mM}$ EDTA, $10 \mathrm{mM} \mathrm{NaCl}$, $0.5 \% \mathrm{SDS}, 100 \mu \mathrm{g} / \mathrm{ml}$ proteinase $\mathrm{K}$ ) and incubated at $50^{\circ} \mathrm{C}$ for
$2 \mathrm{~h}$. The crude DNA preparations were further extracted and precipitated. The DNA pellets were air-dried and re-suspended in $100 \mu \mathrm{l}$ TE buffer (10 mM Tris-HCl, pH 8.0, 1 mM EDTA) containing $100 \mathrm{ng} / \mathrm{ml}$ RNase. The concentration of nucleic acid was determined by UV absorbance at $260 \mathrm{~nm}$. The same amount of nucleic acids from each sample was detected by electrophoresis on a $1.5 \%$ agarose gel and visualized by UV fluorescence after staining with ethidium bromide. Gel was visualized and photographed on an image analyzer instrument (Alpha Innotech Corp., San Leandro, USA).

Hoechest 33342 plus propidium iodide (PI) staining. DRP-1 WT and DRP-1 K38A cells were planted in 96-well plates and cultured in the presence or absence of $500 \mathrm{ng} / \mathrm{ml}$ doxycycline for $48 \mathrm{~h}$, and then treated with or without $4 \mu \mathrm{g} / \mathrm{ml} \mathrm{TM}$ for $36 \mathrm{~h}$. These cells were washed twice with PBS and exposed to Hoechst $33342(10 \mu \mathrm{g} / \mathrm{ml})$ and PI $(10 \mu \mathrm{g} / \mathrm{ml})$, and their fluorescence was examined using a fluorescence microscope with ultraviolet excitation at $340-380 \mathrm{~nm}$. Viable or early apoptotic cells were identified by their nuclei with blue (Hoechst 33342) fluorescence. Late apoptotic or necrotic cells were detected by their nuclei that exhibited red PI fluorescence.

Assessment of phosphatidylserine exposure and mitochondrial membrane potential $\left(\Delta \Psi_{m}\right)$. DRP-1 WT and DRP-1 K38A cells were planted in 6-well plates and cultured in the presence or absence of $500 \mathrm{ng} / \mathrm{ml}$ doxycycline for $48 \mathrm{~h}$, and then treated with or without $4 \mu \mathrm{g} / \mathrm{ml} \mathrm{TM}$ for $24 \mathrm{~h}$. The cells were washed once in PBS and incubated with $10 \mu \mathrm{l}$ $(20 \mu \mathrm{g} / \mathrm{ml})$ Annexin V-FITC according to the manufacturer's instructions. The cells were incubated with $5 \mu \mathrm{l}(50 \mu \mathrm{g} / \mathrm{ml})$ PI for 2 min on ice and then analyzed by FACScan (Beckman, Counter Epics XL, USA). This assay discriminates between intact cells (FITC/PI-), early apoptotic cells $\left(\mathrm{FITC}^{+} / \mathrm{PI}\right)^{-}$, and late apoptotic or necrotic cells $\left(\mathrm{FITC}^{+} / \mathrm{PI}^{+}\right.$or $\left.\mathrm{PI}^{+}\right)$.

To measure the $\Delta \Psi_{\mathrm{m}}$, DRP-1 WT or DRP-1 K38A cells were loaded with $10 \mathrm{nM} \mathrm{DiOC}(3)$ at $37^{\circ} \mathrm{C}$ for $5 \mathrm{~min}$. The cells were washed once and re-suspended in PBS for flow cytometric analysis. The cells treated with the mitochondrial membrane uncoupler carbonyl cyanide-m-chlorophenyl hydrazone (mCCP) for $20 \mathrm{~min}$ at $37^{\circ} \mathrm{C}$ were used as a positive control for dissipation of the $\Delta \Psi_{\mathrm{m}}$.

Detection of cytochrome c release. Detection of mitochondrial cytochrome $\mathrm{c}$ release was performed as previously described (20). Briefly, DRP-1 WT or DRP-1 K38A cells were cultured in T75 flasks for $48 \mathrm{~h}$ in the presence or absence of $500 \mathrm{ng} / \mathrm{ml}$ doxycycline, and then treated with or without TM $(4 \mu \mathrm{g} / \mathrm{ml})$ for $24 \mathrm{~h}$. The cells were harvested and suspended in buffer A (20 mM HEPES-KOH, pH 7.5, $10 \mathrm{mM} \mathrm{KCl}, 1.5 \mathrm{mM}$ $\mathrm{MgCl}_{2}, 1 \mathrm{mM}$ EDTA, $1 \mathrm{mM}$ EGTA, $1 \mathrm{mM}$ dithiothreitol, $250 \mathrm{mM}$ sucrose, $1 \mathrm{mM}$ phenylmethylsulfonyl fluoride) and lysed by a sonicator. The lysate was centrifuged at $1,000 \mathrm{xg}$ for $10 \mathrm{~min}$ at $4^{\circ} \mathrm{C}$ and the supernatant was collected for further centrifugation at $13,000 \mathrm{x}$ g for $20 \mathrm{~min}$. The protein content in the supernatant was determined using the BCA Micro Protein Assay kit (Biyuntian Co., Beijing, China). The cytosolic proteins (supernatant fractions) were separated by 15\% SDS-PAGE and analyzed by Western blotting with a polyclonal antibody against cytochrome c (Santa Cruz, USA). 
Confocal microscopy. DRP-1 WT and DRP-1 K38A cells were cultured in the presence or absence of $500 \mathrm{ng} / \mathrm{ml}$ doxycycline for $48 \mathrm{~h}$, and then treated with or without $4 \mu \mathrm{g} / \mathrm{ml} \mathrm{TM}$ for $24 \mathrm{~h}$. These cells were washed once in PBS and incubated with $1 \mu \mathrm{M}$ MitoTracker Red at $37^{\circ} \mathrm{C}$ for $15 \mathrm{~min}$, and then fixed with $4 \%$ formaldehyde for $15 \mathrm{~min}$ at room temperature. The cells were also stained with an anti-cytochrome c FITCconjugated antibody as previously described (21). The cells were viewed under a confocal microscope (Olympus IX81). Multitrack scanning mode was used to record double-labeled cells.

Measurement of caspase-3 activity. DRP-1 WT and DRP-1 K38A cells were cultured in 6-well plates in the presence or absence of $500 \mathrm{ng} / \mathrm{ml}$ doxycycline for $48 \mathrm{~h}$, and then treated with or without $4 \mu \mathrm{g} / \mathrm{ml} \mathrm{TM}$ for $24 \mathrm{~h}$. The cells were harvested and washed three times with PBS. Caspase-3 activity was measured by a caspase-3 assay kit (Molecular Probes, Invitrogen, USA) following the manufacturer's protocol, and then detected by a microplate fluorescence reader (Molecular Devices Corp., Sunnyvale, CA, USA).

Reactive oxygen species (ROS) assay by flow cytometry. ROS formation was analyzed by flow cytometry according to a previously described method (22). DRP-1 WT and DRP-1 K38A cells were cultured in 6-well plates in the presence or absence of $500 \mathrm{ng} / \mathrm{ml}$ doxycycline for $48 \mathrm{~h}$, and then treated with or without $4 \mu \mathrm{g} / \mathrm{ml} \mathrm{TM}$ for $24 \mathrm{~h}$ at $37^{\circ} \mathrm{C}$ in a $5 \%$ $\mathrm{CO}_{2}$ incubator. Cells were washed twice with PBS, stained with CM-H ${ }_{2}$ DCFDA $(1 \mathrm{mM})$ in PBS (pH 7.2) at $37^{\circ} \mathrm{C}$ for $5 \mathrm{~min}$ and PI $(10 \mathrm{mg} / \mathrm{ml})$ was then added for $1 \mathrm{~min}$. Flow cytometric analysis (Becton-Dickinson, San Jose, CA, USA) was performed at an excitation wavelength of $488 \mathrm{~nm}$ and an emission wavelength of $535 \mathrm{~nm}$.

Statistics. Statistical analyses were performed with the GraphPad Prism software (Graphpad Software, San Diego, $\mathrm{CA})$. The results are expressed as the mean $\pm \mathrm{SD}$ and the Mann-Whitney U test was used to evaluate the differences between groups. P-values of $<0.05$ were taken to denote statistical significance.

\section{Results}

Time-course and dose-response of TG-and TM-induced apoptosis in INS-r $\beta$ cells. To investigate the effect of ER stress on pancreatic $\beta$-cell apoptosis, we used the classic ER stress-producers, TG and TM to cause ER stress in INS-r $\beta$ cells. They both induced INS-r $\beta$ cells apoptosis in a time- and dose-dependent manner (Fig. 1), which was consistent with previous studies $(23,24)$.

ER stress induced DRP-1 expression in INS-r $\beta$ cells. To investigate the possible involvement of DRP-1 in ER stress-induced $\beta$-cell apoptosis, we used Western blotting to analyze the effect of ER stress on DRP-1 expression in INS-r $\beta$ cells. As shown in Fig. 2, endogenous DRP-1 protein was up-regulated by the classic ER stress-producers, TG and TM in a dose- and time-dependent manner. These data suggest that DRP-1 may participate in the ER stress-induced $\beta$-cell apoptosis.
A

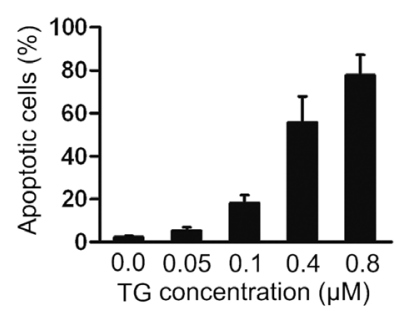

$\mathrm{C}$

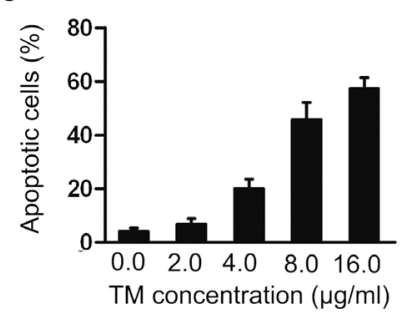

B

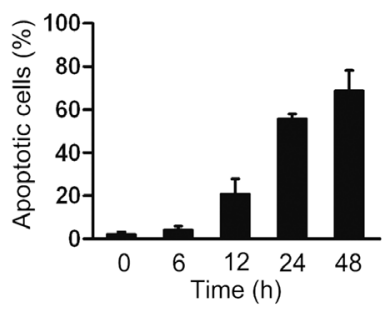

D

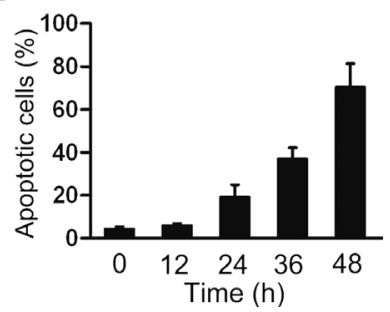

Figure 1. The classic ER stress-producer tunicamycin (TM) and thapsigargin (TG) induced INS-r $\beta$ cells apoptosis in a dose- and time-dependent manner. Analysis for apoptosis in INS-r $\beta$ cells by Annexin V-PI double staining. Data are represented as the mean \pm SD of three independent experiments. (A) Dose-response of TG induced apoptosis in INS-r $\beta$ cells. For studying dose-response, cells were cultured with the indicated doses of TG for $12 \mathrm{~h}$. (B) Time-course of TG induced apoptosis in INS-r $\beta$ cells. For studying the time- course, cells were cultured in a medium containing $0.1 \mu \mathrm{M}$ TG at the indicated times. (C) Dose-response of TM-induced apoptosis in INS-r $\beta$-cells. Cells were cultured with the indicated doses of TM for $24 \mathrm{~h}$ (D) Time-course of TM induced apoptosis in INS-r $\beta$ cells. For studying the time-course, cells were cultured in a medium containing $4 \mu \mathrm{g} / \mathrm{ml} \mathrm{TM}$ at the indicated times.

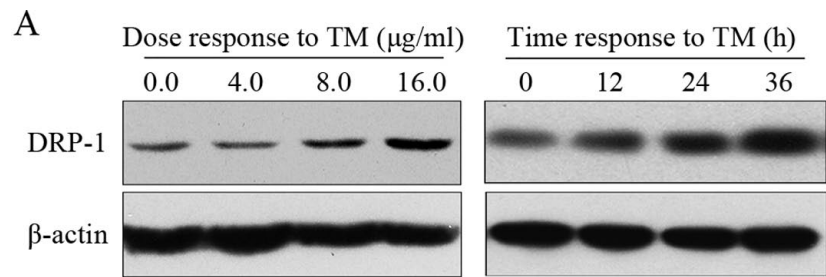

B

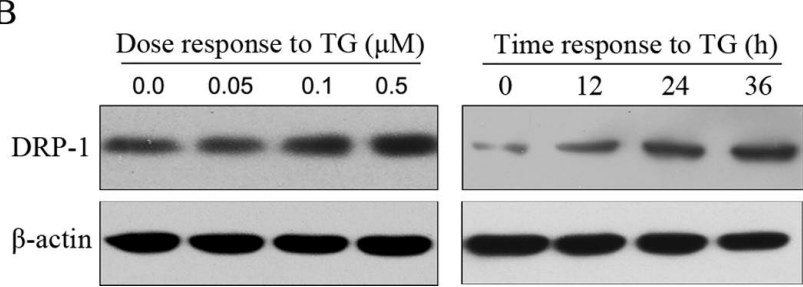

Figure 2. Western blotting was used to analyze the effect of ER stress on DRP-1 expression in INS-r $\beta$ cells. (A) Dose-response and time-course of TM on DRP-1 expression. For studying the dose-response, cells were cultured with the indicated doses of TM for $24 \mathrm{~h}$. For studying the time-course, cells were cultured in a medium containing $4 \mu \mathrm{g} / \mathrm{ml} \mathrm{TM}$ at the indicated times. (B) Dose-response and time-course of TG on DRP-1 expression. For studying dose-response, cells were cultured with the indicated doses of TG for $12 \mathrm{~h}$. For studying the time-course, cells were cultured in a medium containing $0.1 \mu \mathrm{M}$ TG at the indicated times.

Characterization of the DRP-1 WT and DRP-1 K38A inducible cell lines. To investigate whether DRP-1 is implicated in ER stress-induced $\beta$-cell apoptosis, we established two stable cell lines that allow inducible expression of DRP-1 WT or 
A
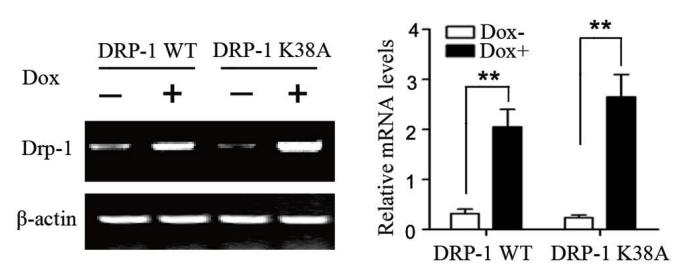

C
Dox +

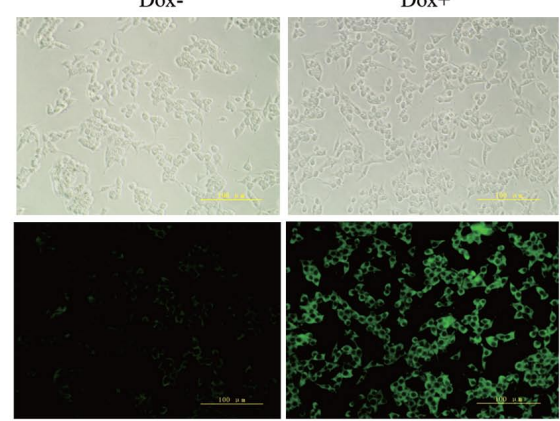

DRP-1 WT

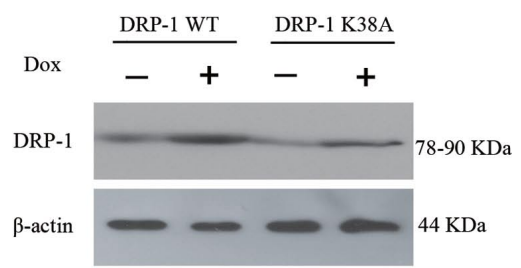

Dox-

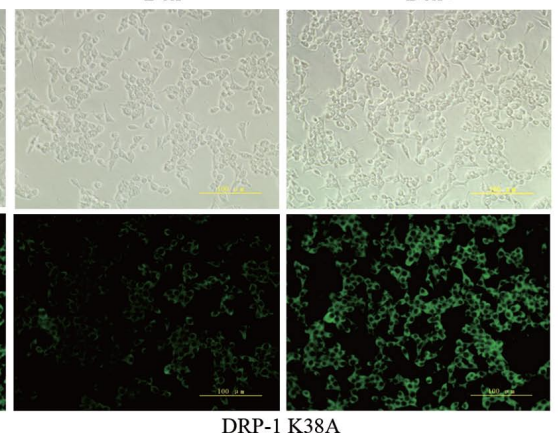

Figure 3. Characterization of the DRP-1 WT and DRP-1 K38A inducible $\beta$-cell lines. (A) Real-time PCR for doxycycline induced Drp-1 mRNA expression in DRP-1 WT and DRP-1 K38A cells. Data represent three independent experiments. ${ }^{* *} \mathrm{p}<0.01$. (B) Western blot analysis for doxycycline (Dox)-induced DRP-1 protein expression in DRP-1 WT and DRP-1 K38A cells. (C) DRP-1 WT and DRP-1 K38A proteins were induced by doxycycline. Phase-contrast images (top) and immunofluorescence staining (bottom).

A
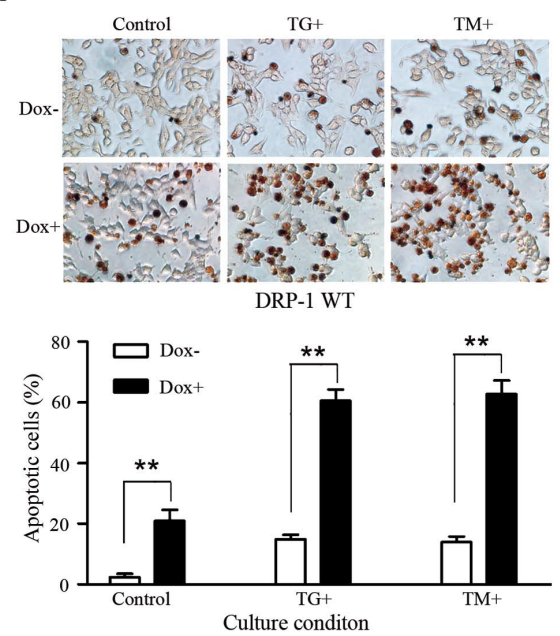

$\mathrm{C}$

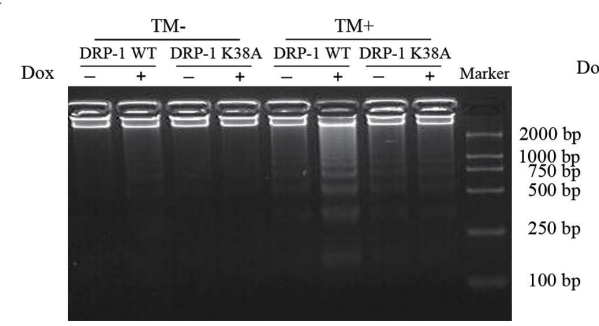

B
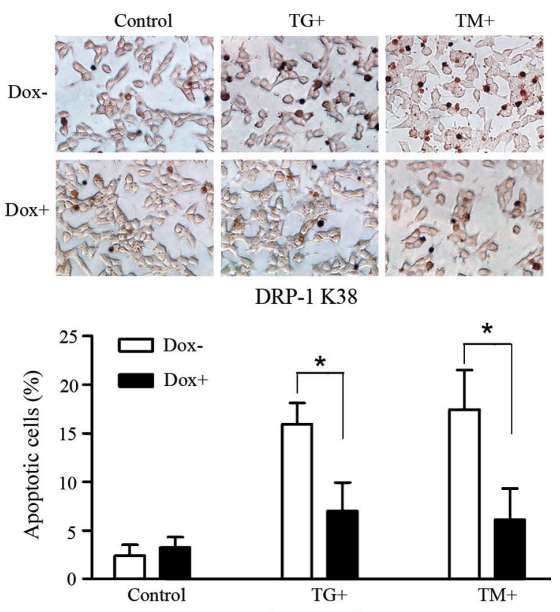

$\mathrm{D}$

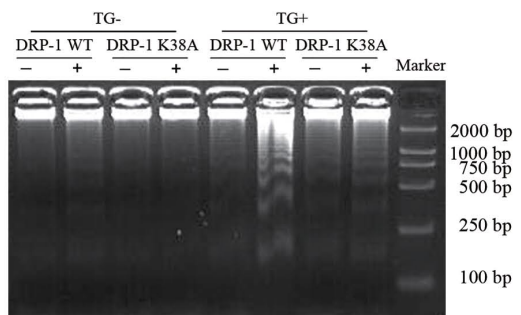

Figure 4. Analysis for apoptosis in DRP-1 WT and DRP-1 K38A cells by TUNEL staining and DNA fragmentation. (A and B) TUNEL staining for apoptosis in DRP-1 WT cells (A) and in DRP-1 K38A cells (B), Data are represented as the mean \pm SD of three independent experiments. ${ }^{*} \mathrm{p}<0.05$, ${ }^{* *} \mathrm{p}<0.01$. DRP-1 WT and DRP-1 K38A cells were cultured in the presence or absence of $500 \mathrm{ng} / \mathrm{ml}$ doxycycline for $48 \mathrm{~h}$, and then treated with $0.1 \mu \mathrm{M}$ TG for $12 \mathrm{~h}$ or $4 \mu \mathrm{g} / \mathrm{ml} \mathrm{TM}$ for $24 \mathrm{~h}$. (C and D) Comparison of DNA fragmentation for apoptosis in DRP-1 WT and DRP-1 K38A cells. Cells were cultured in the presence or absence of $500 \mathrm{ng} / \mathrm{ml}$ doxycycline for $48 \mathrm{~h}$, and then treated with $4 \mu \mathrm{g} / \mathrm{ml} \mathrm{TM}$ for $24 \mathrm{~h}$ (C) or $0.1 \mu \mathrm{M}$ TG for $12 \mathrm{~h}$ (D).

DRP-1 K38A, respectively. The INS-r $\beta$ cells were co-transfected with pUHD10-3 plasmids (25), carrying DRP-1 WT or DRP-1 K38A, and with the pTKHygro plasmid containing the hygromycin-resistance marker. Hygromycin-resistant clones were screened by Northern blotting for clones positively expressing DRP-1 WT or DRP-1 K38A after induction 


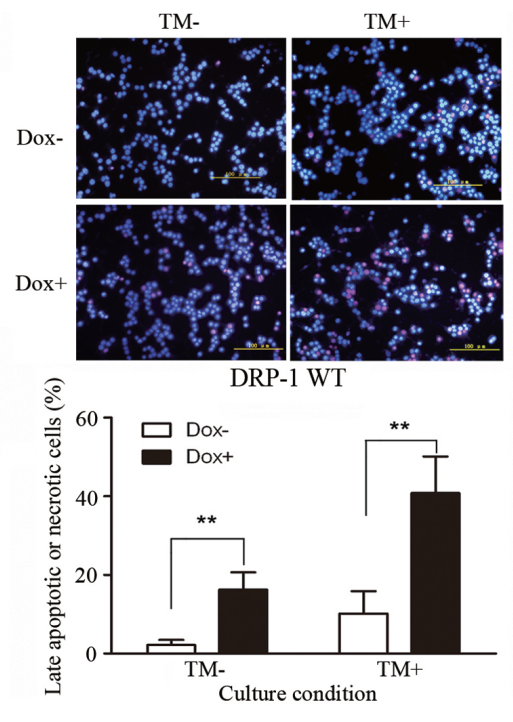

$\mathrm{C}$
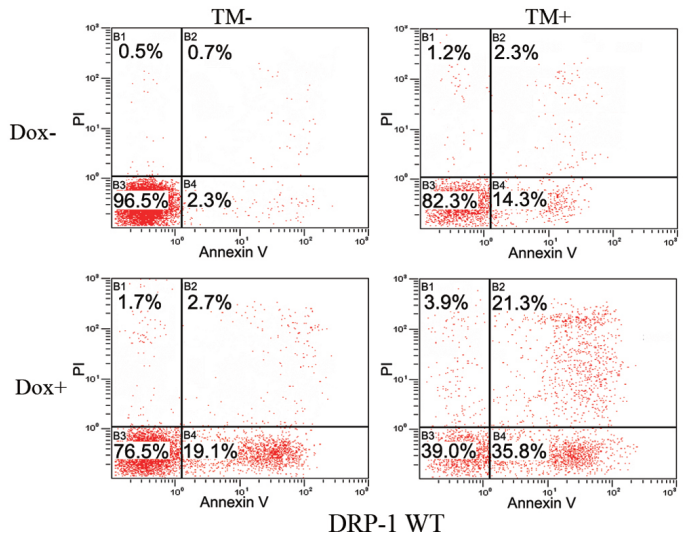

B
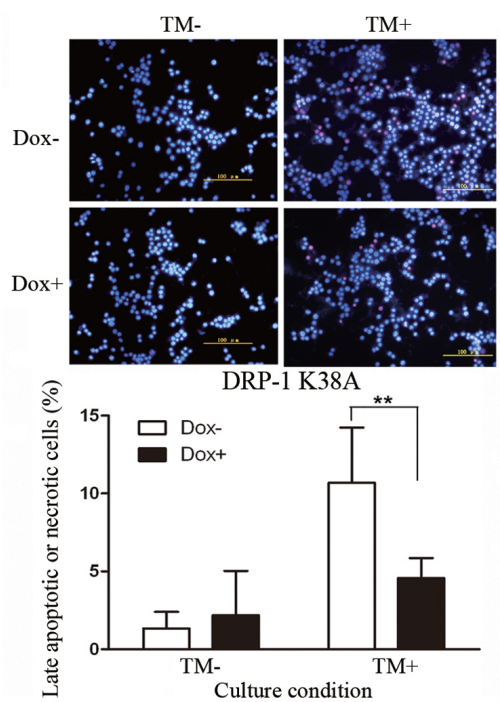

$\mathrm{D}$
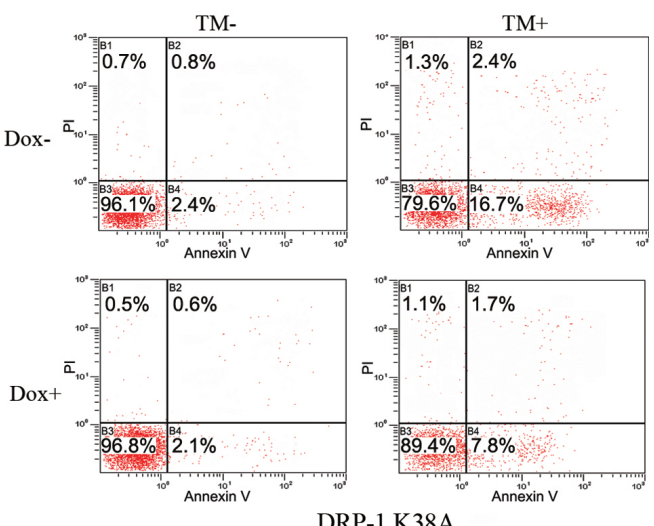

Figure 5. Analysis for apoptosis in DRP-1 WT and DRP-1 K38A cells by Hochest 33342 plus PI staining and Annexin V-PI double staining. (A and B) Hochest 33342 plus PI staining for apoptosis in DRP-1 WT cells (A) and in DRP-1 K38A cells (B). Cells were cultured in the presence or absence of 500 ng/ $\mathrm{ml}$ doxycycline for $48 \mathrm{~h}$, and then treated with or without $4 \mu \mathrm{g} / \mathrm{ml} \mathrm{TM}$ for $36 \mathrm{~h}$. Viable or early apoptotic cells were identified by their nuclei with blue (Hoechst 33342) fluorescence. Late apoptotic or necrotic cells were detected by their nuclei that exhibited red (PI) fluorescence. Data are represented as the mean \pm SD of three independent experiments. ${ }^{* *} \mathrm{p}<0.01$. (C and D) Flow cytometric analysis for apoptosis in DRP-1 WT cells (C) and in DRP-1 K38A cells (D). DRP-1 WT and DRP-1 K38A cells were cultured in the presence or absence of $500 \mathrm{ng} / \mathrm{ml}$ doxycycline for $48 \mathrm{~h}$, and then treated with or without $4 \mu \mathrm{g} / \mathrm{ml}$ TM for $24 \mathrm{~h}$. This assay discriminates between intact cells (FITC-/PI'), early apoptotic cells (FITC $\left./ \mathrm{PI}^{-}\right)$, and late apoptotic or necrotic cells $\left(\mathrm{FITC}^{+} / \mathrm{PI}^{+}\right.$or $\left.\mathrm{PI}^{+}\right)$.

with doxycycline. Two cell clones, named, DRP-1 WT and DRP-1 K38A, which show high-level induction and the lowest background, were selected for the present study. The cells were induced with $500 \mathrm{ng} / \mathrm{ml}$ of doxycycline for $48 \mathrm{~h}$ and the Drp-1 expression was analyzed by real-time PCR (Fig. 3A), Western blotting (Fig. 3B) and immunofluorescence staining (Fig. 3C). As shown in Fig. 3, doxycycline could markedly induce the Drp-1 mRNA and protein expression. However, doxycycline alone did not affect endogenous Drp-1 expression in control INS-r $\beta$ cells (data not shown).

DRP-1-mediated ER stress-induced apoptosis in pancreatic $\beta$-cells. To further investigate the possible involvement of DRP-1 in ER stress-induced $\beta$-cell apoptosis, we studied the apoptosis in DRP-1 WT and DRP-1 K38A cells using TUNEL staining (Fig. 4A and B), DNA fragmentation (Fig. 4C and D), Hochest 33342 plus PI staining (Fig. 5A and B) and Annexin V-PI double staining (Fig. 5C and D). Induction of DRP-1 WT resulted in $\beta$-cell apoptosis, which was significantly enhanced by ER stress. In contrast, DRP-1 K38A did not cause $\beta$-cell. Instead, it partially prevented ER stress-evoked apoptosis in $\beta$-cells (Figs. 4 and 5). These results suggest that DRP-1 is involved in ER stress-induced $\beta$-cell apoptosis. Since DRP-1 plays an important role in activating the mitochondrial apoptosis pathway, the mechanisms underlying DRP-1 involvement in ER stress-induced $\beta$-cell apoptosis were further investigated.

\section{The molecular mechanisms underlying DRP-1-mediated ER} stress-induced apoptosis

Activation of the mitochondrial apoptosis pathway. The $\Delta \Psi_{\mathrm{m}}$ was measured by flow cytometry using the potential-sensitive probe, $\mathrm{DiOC}_{6}(3)$ (26). As shown in Fig. 7, induction of DRP-1 WT, but not DRP-1 K38A led to $\Delta \Psi_{\mathrm{m}}$ depolarization in $\beta$-cells cultured under ER stress conditions (Fig. 6). These data are consistent with the reports that mitochondria eventually depolarize during the release of cytochrome $\mathrm{c}$ and the activation of the caspase cascade (27-29).

Cytochrome c release and intracellular redistribution. Confocal microscopy and Western blotting showed that 
$\mathrm{A}$

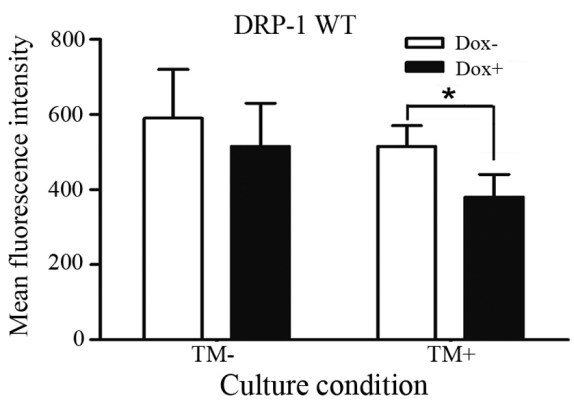

$\mathrm{B}$

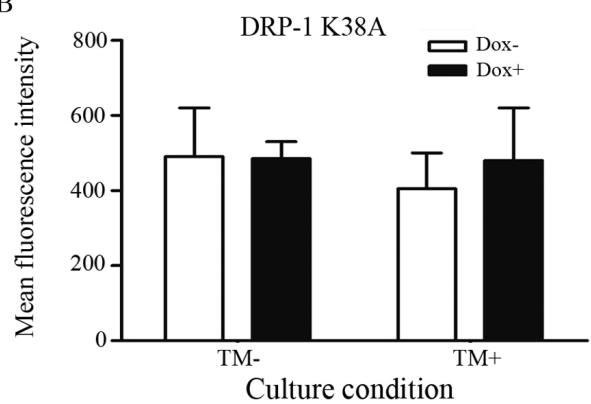

Figure 6. Effect of DRP-1 overexpression on mitochondrial membrane potential $\left(\Delta \Psi_{\mathrm{m}}\right)$ in DRP-1 WT and DRP-1 K38A cells. Data are represented as the mean \pm SD of three independent experiments. " $\mathrm{p}<0.05$.

A

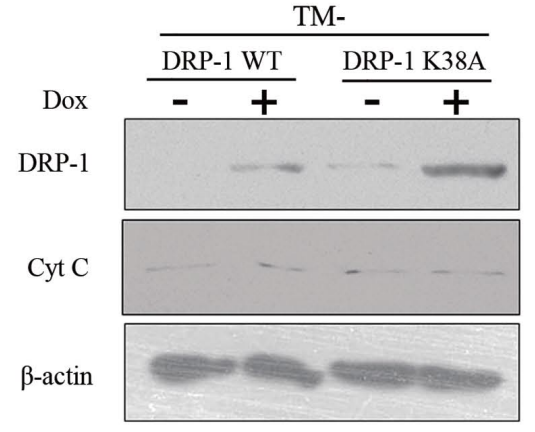

B

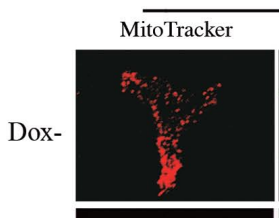

TM-

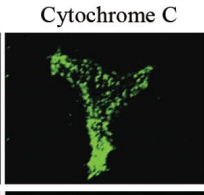

Dox+
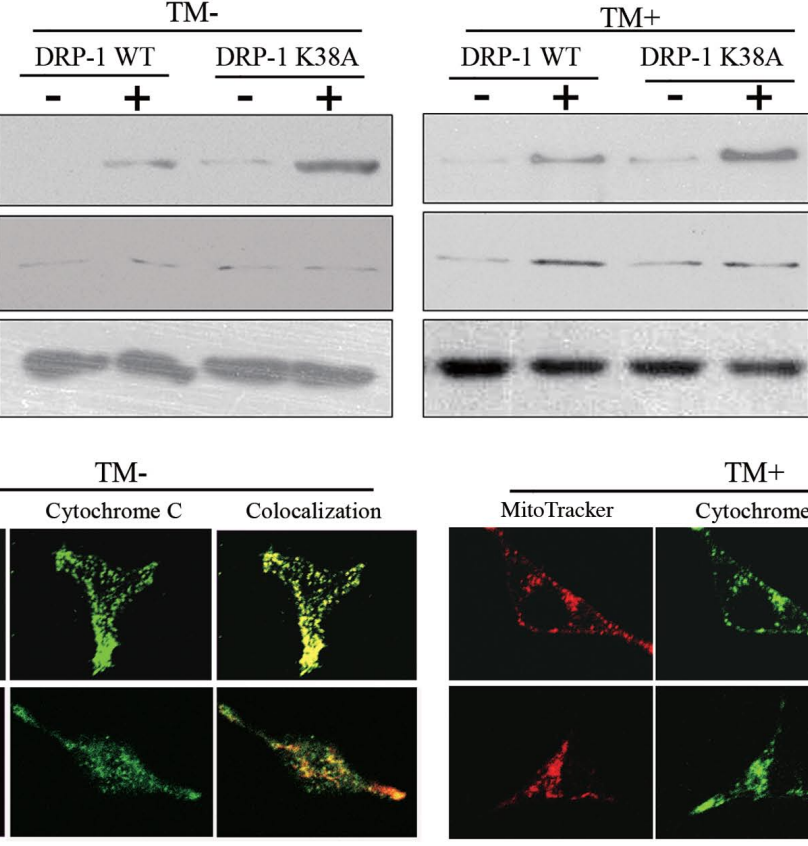

78-90 KDa

$15 \mathrm{KDa}$

$44 \mathrm{KDa}$

$\mathrm{TM}+$

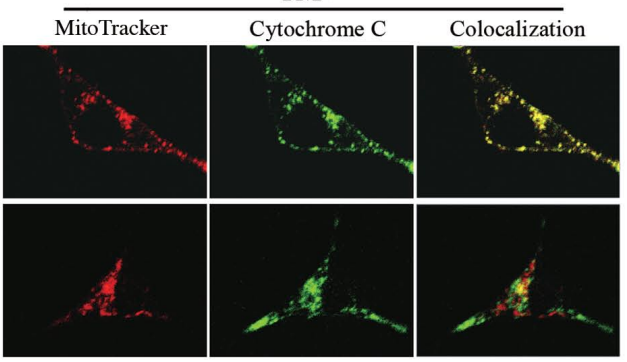

DRP-1 WT

C

TM-
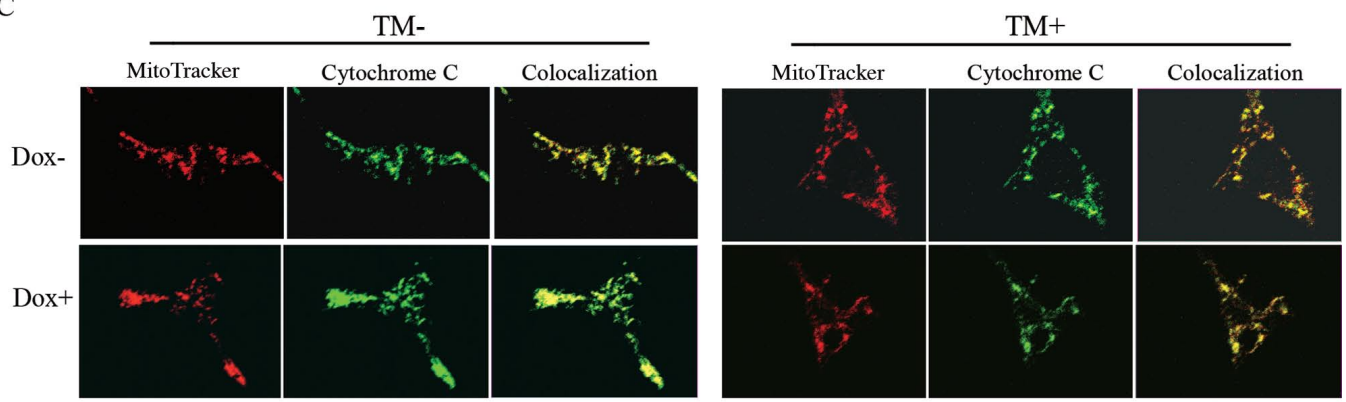

DRP-1 K38A

Figure 7. The effect of DRP-1 on cytochrome $\mathrm{c}$ release and redistribution in $\beta$-cells. (A) Western blot for the release of cytochrome $\mathrm{c}$ from mitochondria in DRP-1 WT and DRP-1 K38A cells. (B) Confocal microscopy for cytochrome c redistribution in DRP-1 WT cells. Red: mitochondrial staining with MitoTracker Red. Green, cytochrome c stained with FITC. (C) Confocal microscopy for cytochrome c redistribution in DRP-1 K38A cells. Red, mitochondrial staining with MitoTracker Red. Green, cytochrome c stained with FITC.

induction of DRP-1 WT led to mitochondrial cytochrome c release and intracellular redistribution under ER stress conditions. However, the release and redistribution of cytochrome $\mathrm{c}$ were not seen in DRP-1 K38A cells under the same conditions (Fig. 7). These results suggest that DRP-1 mediates ER stress-induced apoptosis through cytochrome c release and redistribution.
Production of ROS. To assess whether ROS are involved in DRP-1 induced $\beta$-cell apoptosis, production of ROS was analyzed by flow cytometry in DRP-1 WT and K38A cells under ER stress. Flow cytometric analysis showed that induction of DRP-1 WT enhanced ER stress-induced ROS production in $\beta$-cells, whereas induction of DRP-1 K38A inhibited the ROS generation in $\beta$-cells under the same condition (Fig. 8A and B). 


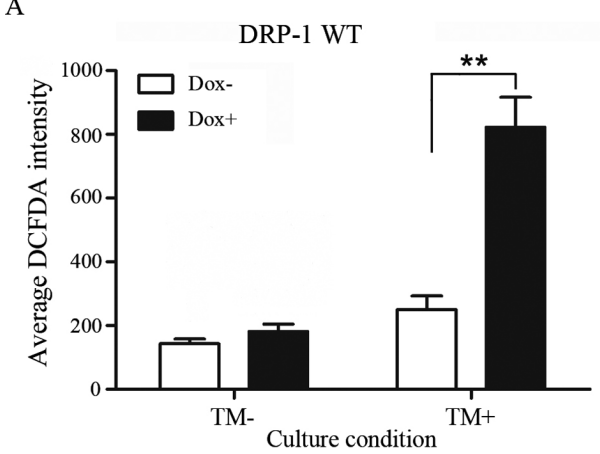

$\mathrm{C}$

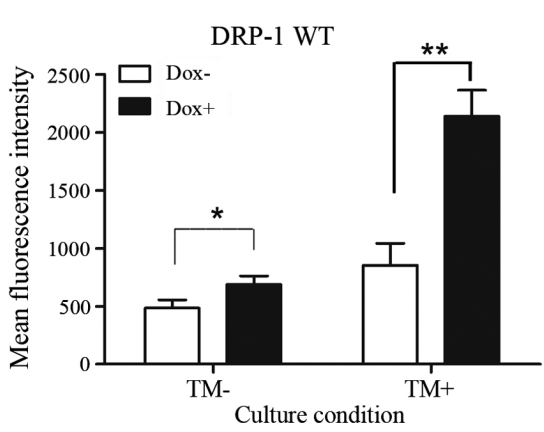

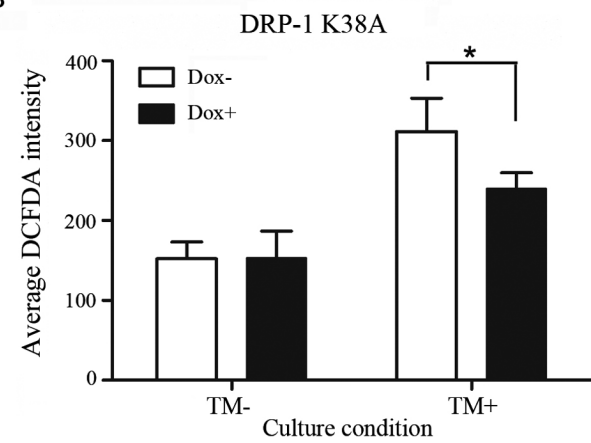

$\mathrm{D}$

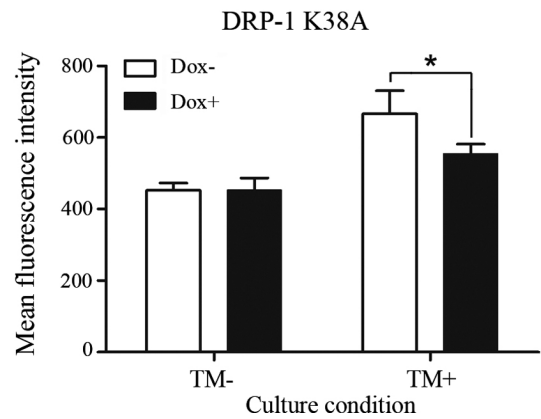

Figure 8. The effect of DRP-1 on ROS production and caspase-3 activity in DRP-1 WT and DRP-1 K38A cells. Data are represented as the mean \pm SD of six independent experiments. " $\mathrm{p}<0.01$; " $\mathrm{p}<0.05$. (A and B) The effect of DRP-1 on ROS production in DRP-1 WT (A) and DRP-1 K38A cells (B). (C and D) The effect of DRP-1 expression on caspase-3 activity in DRP-1 WT cells (C) and DRP-1 K38A cells (D).

Activation of the executioner caspase-3. To further assess whether activation of the executioner caspase was involved in DRP-1 induced $\beta$-cell apoptosis, caspase-3 activity was measured by monitoring the cleavage of a fluorigenic caspase substrate in DRP-1 WT and DRP-1 K38A cells under ER stress. These results show that induction of DRP-1 WT enhanced ER stress-induced caspase-3 activation, whereas induction of DRP-1 K38A prevented the caspase-3 activation in $\beta$-cells (Fig. 8C and D).

\section{Discussion}

Type 2 diabetes is characterized by both insulin resistance and $\beta$-cell dysfunction. It has been demonstrated that the $\beta$-cell dysfunction is related to ER stress (23).

The ER is one of the most important organelles in $\beta$-cells which is responsible for several cellular functions, including the synthesis, initial post-translational modification, proper folding and maturation of newly synthesized pro-insulin. Various biochemical and physiological stimuli can induce ER stress. Islet $\beta$-cells are particularly susceptible to ER stress owing to the high rate of insulin synthesis and high development of intercellular ER (30). Although several studies have indicated the physiological role of moderate ER stress in the regulation of insulin synthesis and secretion in $\beta$-cells (3), some recent evidence suggests that strong and long-term ER stress has harmful effects on $\beta$-cell functions (31).

Hom et al have reported that an ER stress inducer could induce fragmentation of mitochondria and cell apoptosis (32). However, whether some protein factors directly participating in mitochondrial fragmentation mediate ER stress-induced $\beta$-cell apoptosis has not been investigated. It has been reported that DRP-1, a key component of the mitochondrial fission machinery, is required for mitochondrial fragmentation and programmed cell death in non- $\beta$-cell and $\beta$-cell apoptosis (33). Our recent study demonstrated that DRP-1 mediates high glucose-induced pancreatic $\beta$-cell apoptosis (13). In addition, the fact that high glucose levels lead to ER stress in $\beta$-cells has been confirmed $(5,34)$. Therefore, whether DRP-1 is also implicated in ER stress-induced pancreatic $\beta$-cell apoptosis should be investigated.

In this study, we demonstrated that DRP-1 is also an important mediator of ER stress-induced $\beta$-cell apoptosis. In order to analyze the effect of DRP-1 expression on ER stressinduced $\beta$-cell apoptosis, we used two established pancreatic $\beta$-cell lines that allow inducible expression of DRP-1 WT and dominant-negative mutant DRP-1 K38A, respectively. The doxycycline inductions of DRP-1 WT and DRP-1 K38A in these cells were demonstrated by real-time PCR, Western blotting and immunofluorescence staining. Under ER stress conditions, we studied the cell apoptosis in DRP-1 WT and DRP-1 K38A cells using TUNEL staining, DNA fragmentation, Hochest 33342 plus PI staining and Annexin V-PI double staining. We have demonstrated that induction of DRP-1 WT alone is sufficient to evoke apoptosis in $\beta$-cells. In addition, up-regulation of DRP-1 WT significantly deteriorated ER stress-induced apoptosis in $\beta$-cells, whereas DRP-1 K38A prevented $\beta$-cell apoptosis. These results confirmed our speculation that DRP-1 plays an important role in the regulation of ER stress-induced apoptosis in $\beta$-cells.

On the basis of our previous study, the mechanisms underlying DRP-1 involvement in ER stress-induced $\beta$-cell apoptosis were further investigated. It was reported that DRP-1, a key component of the mitochondrial fission machinery, is required 
for mitochondrial fragmentation and ensuing apoptosis (33). In our previous study, we found that DRP-1, which is known to cause mitochondrial fission, resulted in morphological changes of the mitochondria from a long shape into a round and short shape under high glucose conditions. These results suggest that DRP-1 plays an important role in regulation of mitochondrial fission and ensuing apoptosis in $\beta$-cells. Therefore, we proposed that DRP-1 may mediate ER stressinduced apoptosis through mitochondrial fission and ensuing activation of the mitochondrial apoptosis pathway.

It has been shown that mitochondrial fragmentation is required for the release of apoptogenic factors from the mitochondrial intermembrane space. One of the best characterized factors is cytochrome c. It is a soluble protein located in the mitochondrial intermembrane space, which functions as an electron carrier of the mitochondrial respiratory chain between complexes III and IV. Once released into the cytosol, cytochrome $\mathrm{c}$ binds to Apaf-1 to form a complex with caspase-9 (35). This large complex initiates the activation of downstream caspases.

In this study, we have investigated the cytochrome c release and intracellular redistribution. Confocal microscopy and Western blotting showed that DRP-1 WT, but not the DRP-1 K38A led to mitochondrial cytochrome c release and intracellular redistribution under ER stress conditions. Our results also showed that up-regulation of DRP-1 increased ROS production, decreased mitochondrial membrane potential, induced caspase- 3 activation and apoptosis in $\beta$-cells under ER stress conditions. In contrast, under the same conditions, induction of DRP-1 K38A had contrary effect on mitochondrial fragmentation, caspase-3 activation, ROS generation and $\beta$-cell apoptosis. These results suggest that DRP-1-mediated mitochondrial fission is an essential mechanism underlying ER stress.

In summary, our study indicate that increased DRP-1 expression may explain ER stress-induced $\beta$-cell apoptosis. DRP-1 may induce $\beta$-cell apoptosis through the process of mitochondrial fission, cytochrome c release, ROS generation and caspase-3 activation. In contrast, dominant-negative suppression of DRP-1 function by DRP-1 K38A largely prevented ER stress-induced $\beta$-cell apoptosis. The data thus suggest, for the first time, that DRP-1 mediated mitochondrial fission is an essential mechanism underlying ER stress-induced $\beta$-cell apoptosis in type 2 diabetes. Inhibition of DRP-1 function could represent a novel approach for $\beta$-cell protection.

\section{Acknowledgements}

This study was supported by the National Basic Research Program of China (No. 2006CB503906 to J.L.), the HI-TECH Research and Development Program of China (No. 2006AA02A113 to J.L.), the National Nature Science Foundation of China (No. 30971410 to X.M.) and by the Swiss National Foundation (No. 310000 116750/1 to C.B.W).

\section{References}

1. Bruun C, Heding PE, Ronn SG, et al: Suppressor of cytokine signalling-3 inhibits tumor necrosis factor-alpha induced apoptosis and signalling in beta cells. Mol Cell Endocrinol 311: 32-38, 2009.
2. Eizirik DL, Cardozo AK and Cnop M: The role for endoplasmic reticulum stress in diabetes mellitus. Endocr Rev 29: 42-61, 2008.

3. Harding HP, Zeng H, Zhang Y, et al: Diabetes mellitus and exocrine pancreatic dysfunction in perk-/- mice reveals a role for translational control in secretory cell survival. Mol Cell 7: 1153-1163, 2001.

4. Laybutt DR, Preston AM, Akerfeldt MC, et al: Endoplasmic reticulum stress contributes to beta cell apoptosis in type 2 diabetes. Diabetologia 50: 752-763, 2007.

5. Marchetti P, Bugliani M, Lupi R, et al: The endoplasmic reticulum in pancreatic beta cells of type 2 diabetes patients. Diabetologia 50: 2486-2494, 2007.

6. Hwang DY, Seo S, Kim Y, et al: Significant change in insulin production, glucose tolerance and ER stress signaling in transgenic mice coexpressing insulin-siRNA and human IDE. Int $\mathrm{J}$ Mol Med 19: 65-73, 2007.

7. Fine EL, Horal M, Chang TI, Fortin G and Loeken MR: Evidence that elevated glucose causes altered gene expression, apoptosis, and neural tube defects in a mouse model of diabetic pregnancy. Diabetes 48: 2454-2462, 1999.

8. Koyama M, Wada R, Sakuraba H, Mizukami H and Yagihashi S: Accelerated loss of islet beta cells in sucrose-fed Goto-Kakizaki rats, a genetic model of non-insulin-dependent diabetes mellitus. Am J Pathol 153: 537-545, 1998.

9. Molina AJ, Wikstrom JD, Stiles L, et al: Mitochondrial networking protects beta-cells from nutrient-induced apoptosis. Diabetes 58: 2303-2315, 2009.

10. Pick A, Clark J, Kubstrup C, et al: Role of apoptosis in failure of beta-cell mass compensation for insulin resistance and beta-cell defects in the male Zucker diabetic fatty rat. Diabetes 47 : 358-364, 1998.

11. Martinou JC and Youle RJ: Which came first, the cytochrome c release or the mitochondrial fission? Cell Death Differ 13: 1291-1295, 2006.

12. Youle RJ and Karbowski M: Mitochondrial fission in apoptosis. Nat Rev Mol Cell Biol 6: 657-663, 2005.

13. Men X, Wang H, Li M, et al: Dynamin-related protein 1 mediates high glucose induced pancreatic beta cell apoptosis. Int J Biochem Cell Biol 41: 879-890, 2009.

14. Smirnova E, Shurland DL, Ryazantsev SN and van der Bliek AM: A human dynamin-related protein controls the distribution of mitochondria. J Cell Biol 143: 351-358, 1998.

15. Gossen M, Freundlieb S, Bender G, Muller G, Hillen W and Bujard $\mathrm{H}$ : Transcriptional activation by tetracyclines in mammalian cells. Science 268: 1766-1769, 1995.

16. Wang $\mathrm{H}$ and Iynedjian PB: Modulation of glucose responsiveness of insulinoma beta-cells by graded overexpression of glucokinase. Proc Natl Acad Sci USA 94: 4372-4377, 1997.

17. Wang H, Maechler P, Ritz-Laser B, et al: Pdx1 level defines pancreatic gene expression pattern and cell lineage differentiation. J Biol Chem 276: 25279-25286, 2001.

18. Asfari M, Janjic D, Meda P, Li G, Halban PA and Wollheim CB: Establishment of 2-mercaptoethanol-dependent differentiated insulin-secreting cell lines. Endocrinology 130: 167-178, 1992.

19. Wang H, Maechler P, Hagenfeldt KA and Wollheim CB: Dominant-negative suppression of HNF-1alpha function results in defective insulin gene transcription and impaired metabolismsecretion coupling in a pancreatic beta-cell line. EMBO J 17: 6701-6713, 1998.

20. Yang J, Liu X, Bhalla K, et al: Prevention of apoptosis by Bcl-2: release of cytochrome $\mathrm{c}$ from mitochondria blocked. Science 275: 1129-1132, 1997.

21. Santel A and Fuller MT: Control of mitochondrial morphology by a human mitofusin. J Cell Sci 114: 867-874, 2001

22. Chen Q, Chai YC, Mazumder S, et al: The late increase in intracellular free radical oxygen species during apoptosis is associated with cytochrome $\mathrm{c}$ release, caspase activation, and mitochondrial dysfunction. Cell Death Differ 10: 323-334, 2003.

23. Fonseca SG, Burcin M, Gromada J and Urano F: Endoplasmic reticulum stress in beta-cells and development of diabetes. Curr Opin Pharmacol 9: 763-770, 2009.

24. Qian B, Wang H, Men X, et al: TRIB3 (corrected) is implicated in glucotoxicity- and endoplasmic reticulum-stress-induced (corrected beta-cell apoptosis. J Endocrinol 199: 407-416, 2008.

25. Huan JY and Koop DR: Tightly regulated and inducible expression of rabbit CYP2E1 using a tetracycline-controlled expression system. Drug Metab Dispos 27: 549-554, 1999.

26. Frank S, Gaume B, Bergmann-Leitner ES, et al: The role of dynamin-related protein 1, a mediator of mitochondrial fission, in apoptosis. Dev Cell 1: 515-525, 2001. 
27. Krohn AJ, Wahlbrink T and Prehn JH: Mitochondrial depolarization is not required for neuronal apoptosis. J Neurosci 19: 7394-7404, 1999

28. Bossy-Wetzel E, Newmeyer DD and Green DR: Mitochondrial cytochrome c release in apoptosis occurs upstream of DEVDspecific caspase activation and independently of mitochondrial transmembrane depolarization. EMBO J 17: 7-49, 1998.

29. Goldstein JC, Waterhouse NJ, Juin P, Evan GI and Green DR: The coordinate release of cytochrome $\mathrm{c}$ during apoptosis is rapid, complete and kinetically invariant. Nat Cell Biol 2: 156-162, 2000.

30. Scheuner D, Vander MD, Song B, et al: Control of mRNA translation preserves endoplasmic reticulum function in beta cells and maintains glucose homeostasis. Nat Med 11: 757-764, 2005.

31. Hou ZQ, Li HL, Gao L, Pan L, Zhao JJ and Li GW: Involvement of chronic stresses in rat islet and INS-1 cell glucotoxicity induced by intermittent high glucose. Mol Cell Endocrinol 291: 71-78, 2008.
32. Hom JR, Gewandter JS, Michael L, Sheu SS and Yoon Y: Thapsigargin induces biphasic fragmentation of mitochondria through calcium-mediated mitochondrial fission and apoptosis. J Cell Physiol 212: 498-508, 2007.

33. Jagasia R, Grote P, Westermann B and Conradt B: DRP-1mediated mitochondrial fragmentation during EGL-1-induced cell death in C. elegans. Nature 433: 754-760, 2005.

34. Wang H, Kouri G and Wollheim CB: ER stress and SREBP-1 activation are implicated in beta-cell glucolipotoxicity. J Cell Sci 118: 3905-3915, 2005

35. Zou H, Henzel WJ, Liu X, Lutschg A and Wang X: Apaf-1, a human protein homologous to C. elegans CED-4, participates in cytochrome c-dependent activation of caspase-3. Cell 90: 405-413, 1997. 